C.O. McMillan MD, I.A. Spahr-Schopfer MD, N. Sikich RN, E. Hartley MD PhD FRCPC, J. Lerman MD FRCPC

\title{
Premedication of children with oral midazolam
}

In a randomized, double-blind, placebo-controlled study, the safety, efficacy and feasibility of oral midazolam premedication in children were evaluated in an ambulatory surgery unit. Eighty unmedicated children (ASA PS I or II, ages I-6 yr) were randomly assigned to one of four groups receiving midazolam $0.5,0.75$, or $1.0 \mathrm{mg} \cdot \mathrm{kg}^{-1}$ or a placebo $30 \mathrm{~min}$ before separation from parents. Heart rate, systolic blood pressure, arterial oxygen saturation, respiratory rate, sedation and anxiolysis scores were recorded before premedication, every five minutes for $30 \mathrm{~min}$ and then during induction of anaesthesia and recovery. We found that heart rate, systolic blood pressure, arterial oxygen saturation and respiratory rate were unchanged during the study. Sedation and anxiolysis scores in the midazolam-treated groups were greater than those in the placebo group and that anxiolysis at the time of separation from the parents was judged excellent in $80-90 \%$ of the children who received midazolam. However, sedation and anxiolysis did not differ among the three midazolam groups. Mean times to discharge from hospital were similar for all four groups. The side effects, loss of balance and head control, blurred vision and dysphoric reactions were observed only in the 0.75 and $1.0 \mathrm{mg} \cdot \mathrm{kg}^{-1}$ midazolam groups. We conclude that oral midazolam $0.5 \mathrm{mg} \cdot \mathrm{kg}^{-1}$ is a safe and effective premedication and that 0.75 and $1 \mathrm{mg} \cdot \mathrm{kg}^{-1}$ while offering no additional benefit, may cause more side effects.

\section{Key words}

ANAESTHESIA: outpatient, paediatric; ANAESTHETICS, INTRA VENOUS: midazolam; PREMEDICATION: midazolam.

From the Department of Anaesthesia and the Research Institute, The Hospital for Sick Children, University of Toronto, Ontario, Canada.

Supported in part with a grant from Hoffmann-La Roche Ltd, Canada.

Presented in part at the annual meeting of the American

Society of Anesthesiologists, San Francisco, October, 1991.

Address correspondence to: Dr. Jerrold Lerman, Department of Anaesthesia, The Hospital for Sick Children, 555 University Avenue, Toronto, Canada M5G 1 X8.

Accepted for publication 29th January, 1992.
La sécurité, l'efficacité et la possibilité d'utiliser le midazolam oral en prémédication chez les enfants ont été évaluées dans une unité de chirurgie d'un jour, à l'aide d'une étude randomisée, à double insue et comprenant des contrôles placebos. Quatre-vingt enfants non prémédiqués (ASA PS I ou II, âgés entre $I$ et 6 ans) ont été divisés, au hasard, en quatre groupes, recevant du midazolam à des doses de $0,5,0,75$, ou $1 \mathrm{mg} \cdot \mathrm{kg}^{-1}$ ou un placebo 30 minutes avant de quitter leurs parents. La fréquence cardiaque, la tension artérielle systolique, la saturation artérielle, la fréquence respiratoire, ainsi que les pointages de sédation et d'anxiolyse étaient notés avant la prémédication, toutes les 5 minutes pendant 30 minutes et par la suite pendant l'induction et l'émergence de l'anesthésie. Nous avons noté que les fréquences cardiaques, la tension artérielle systolique, la saturation artérielle et la fréquence respiratoire étaient inchangées pendant l'étude. Les pointages de sédation et d'anxiolyse dans les groupes traités avec du midazolam étaient plus élevés que dans le groupe placebo, et l'anxiolyse au moment de quitter les parents était jugée excellente chez 80 à 90\% des enfants qui avaient reçu du midazolam. Cependant, la sédation et l'anxiolyse étaient semblables pour les trois groupes traités avec du midazolam. En moyenne, le congé de l'hôpital survenait au même moment pour les quatre groupes. Les effets secondaires tels la perte d'équilibre, la perte du contrôle de la tête, la vision embrouillée et les réactions dysphoriques n'étaient observés que dans les groupes ayant reçu du midazolam à des doses de 0,75 et $1,0 \mathrm{mg} \cdot \mathrm{kg}^{-1}$. En conclusion, une dose orale de midazolam de $0,5 \mathrm{mg} \cdot \mathrm{kg}^{-1}$ est efficace et sécuritaire en prémédication, mais des doses de 0.75 et $1 \mathrm{mg} \cdot \mathrm{kg}^{-1}$ peuvent causer plus d'effets secondaires tout en n'offrant aucun avantage additionnel.

The ideal premedicant for children scheduled for ambulatory surgery should: (1) be available in a preparation that is readily accepted by the children; (2) have a relatively rapid and reliable onset; (3) provide anxiolysis with mild sedative effects; (4) have anxiolytic and sedative effects of sufficient duration to accommodate delays in operating room scheduling without delaying discharge; (5) be free of side effects that would necessitate high levels of nursing supervision; and (6) provide for a rapid recovery and return to alertness postoperatively, thereby permitting early discharge from the recovery area. The parenteral 
TABLE I Demographic data

\begin{tabular}{lcccc}
\hline \multicolumn{5}{c}{ Midazolam dose } \\
\cline { 2 - 5 } & Placebo & $0.5 \mathrm{mg} \cdot \mathrm{kg}^{-1}$ & $0.75 \mathrm{mg} \cdot \mathrm{kg}^{-1}$ & $1.0 \mathrm{mg} \cdot \mathrm{kg}^{-1}$ \\
\hline Number & 20 & 20 & 20 & 20 \\
Age (yr) & $3.7 \pm 1.3$ & $3.7 \pm 1.4$ & $3.4 \pm 1.5$ & $3.4 \pm 1.5$ \\
Weight (kg) & $15.3 \pm 3.4$ & $16.4 \pm 3.5$ & $11.7 \pm 3.0$ & $15.7 \pm 3.5$ \\
Duration of surgery (min) & $32 \pm 17$ & $38 \pm 19$ & $33 \pm 20$ & $37 \pm 21$ \\
\hline
\end{tabular}

formulation of midazolam has become very popular as an oral premedication in children because it satisfies many of the above characteristics. ${ }^{\prime}$ However, the cardiorespiratory changes associated with this premedication (in the absence of atropine) have not been reported in children. Furthermore, the optimal dose of oral midazolam has not been clearly defined, particularly as it relates to issues of safety and the special needs of a busy ambulatory surgery unit. In a recent study, Feld et al. evaluated the use of oral midazolam premedication in children. ${ }^{1}$ They observed a dose response relationship between midazolam $(0.25$ to 0.75 $\mathrm{mg} \cdot \mathrm{kg}^{-1}$ ) and the sedation and separation scores at induction of anaesthesia. However, ease of separation from parents was rated as excellent in less than $10 \%$ of the children. We, therefore, sought to optimize the efficacy of midazolam premedication and the quality of separation as measured by the sedation and anxiolysis scores and to evaluate the safety and feasibility of a larger dose of midazolam in children scheduled for ambulatory surgery of short duration.

\section{Methods}

This randomized, double-blind, placebo-controlled study was approved by the Institutional Review Board and written parental consent was obtained. Eighty fasted children (ASA PS I or II, ages 1-6 yr) scheduled for minor superficial lower abdominal, plastic or dental surgery lasting approximately $30 \mathrm{~min}$ were studied. Children were excluded if there was a history of upper airway disease, central nervous system dysfunction, gastroesophageal dysmotility or reflux, recent or chronic medication that could interact with midazolam (i.e., sedatives, anticonvulsivants, antibiotics (such as erythromycin)) or known allergies to the drug or the vehicle. The children were assigned to one of four groups ( $n=20$ per group) by random selection. Group I (placebo) received distilled water; Group II received midazolam $0.5 \mathrm{mg} \cdot \mathrm{kg}^{-1}$, Group III received midazolam $0.75 \mathrm{mg} \cdot \mathrm{kg}^{-1}$, Group IV received midazolam $1.0 \mathrm{mg} \cdot \mathrm{kg}^{-1}$. All premedicants including the placebo were administered orally in a volume of a thick chocolate-cherry syrup $(\mathrm{pH}=4.5$ ) equal to the volume of midazolam $\left(5 \mathrm{mg} \cdot \mathrm{ml}^{-1}\right.$ parenteral formulation) $30 \mathrm{~min}$ before surgery. ${ }^{2}$ Heart rate, systolic blood pressure and respiratory rate were measured every five minutes for 20 $\mathrm{min}$ and at $30 \mathrm{~min}$ after premedication. Arterial oxygen saturation was recorded continuously. Untoward effects such as apnoea or airway obstruction were also recorded. The efficacy and safety of oral midazolam were assessed during the $30 \mathrm{~min}$ by a trained observer who was unaware of the treatment. Clinical indices were used to quantitate the efficacy, that is the degree of sedation and the level of anxiolysis during this period. Sedation was measured on a four-point scale $(1=$ alert/active; $2=$ awake $/ \mathrm{calm}$; $3=$ drowsy but responds to verbal/tactile stimulation; $4=$ asleep). Anxiolysis was also measured on a fourpoint scale $(1=$ tearful/combative; $2=$ anxious but easily reassured; $3=$ calm; $4=$ asleep). Thirty minutes after administration of the premedication the children were separated from their parents to assess the effectiveness of the premedication to minimize emotional responses at this time.

On arrival in the operative theatre, presurgical heart rate and systolic blood pressure were measured prior to application of the mask. All children were anaesthetized for surgery in a standardized manner. Anaesthesia was induced using nitrous oxide, halothane and oxygen by mask. The anaesthetists were blinded to the premedication. Mask acceptance was recorded by the same trained observer using the anxiolysis scale. The inspired halothane concentration during surgery was titrated to the minimum concentration required to maintain haemodynamic stability (defined as $\pm 20 \%$ of presurgical heart rate and systolic arterial pressure). No opioids or other sedatives were administered intraoperatively. Muscle relaxants were antagonized at the end of surgery. Regional field blocks were administered whenever feasible. Postoperative analgesia was achieved with either rectal acetaminophen or intramuscular codeine.

During the recovery period, the time interval between the end of surgery and the suitability to transfer to the post-anaesthetic care unit (PACU), the time interval between arrival in PACU and first spontaneous eye opening and the duration of stay in PACU until discharge from the hospital were recorded. During recovery, haemodynamic and respiratory variables were assessed together with the level of consciousness and degree of agitation. 


\begin{tabular}{|c|c|c|c|c|}
\hline & \multirow[b]{2}{*}{ Placebo } & \multicolumn{3}{|c|}{ Midazolam dose } \\
\hline & & $0.5 \mathrm{mg} \cdot \mathrm{kg}^{-1}$ & $0.75 \mathrm{mg} \cdot \mathrm{kg}^{-1}$ & $1.0 \mathrm{mg} \cdot \mathrm{kg}^{-1}$ \\
\hline \multicolumn{5}{|l|}{ Haemodynamics } \\
\hline Initial HR & $112 \pm 20$ & $110 \pm 13$ & $113 \pm 18$ & $108 \pm 20$ \\
\hline HR $30 \mathrm{~min}$ & $112 \pm 16$ & $111 \pm 15$ & $110 \pm 15$ & $105 \pm 12$ \\
\hline PACU-HR 0 min & $126 \pm 16$ & $132 \pm 19$ & $135 \pm 20$ & $132 \pm 19$ \\
\hline PACU-HR $30 \mathrm{~min}$ & $125 \pm 13$ & $131 \pm 26$ & $132 \pm 22$ & $121 \pm 16$ \\
\hline Initial SBP & $93 \pm 15$ & $96 \pm 8$ & $100 \pm 16$ & $96 \pm 7$ \\
\hline SBP $30 \mathrm{~min}$ & $97 \pm 8$ & $95 \pm 6$ & $92 \pm 9$ & $95 \pm 9$ \\
\hline PACU-SBP $0 \mathrm{~min}$ & $90 \pm 14$ & $97 \pm 15$ & $88 \pm 16$ & $90 \pm 9$ \\
\hline PACU-SBP $30 \mathrm{~min}$ & $98 \pm 9$ & $96 \pm 8$ & $94 \pm 11$ & $99 \pm 10$ \\
\hline \multicolumn{5}{|l|}{ Respiratory } \\
\hline Initial RR & $22 \pm 2$ & $24 \pm 4$ & $25 \pm 4$ & $24 \pm 10$ \\
\hline RR $30 \mathrm{~min}$ & $23 \pm 4$ & $27 \pm 6$ & $25 \pm 5$ & $24 \pm 4$ \\
\hline PACU-RR 0 min & $30 \pm 7$ & $30 \pm 10$ & $31 \pm 7$ & $30 \pm 7$ \\
\hline PACU-RR $30 \mathrm{~min}$ & $25 \pm 3$ & $25 \pm 4$ & $27 \pm 4$ & $27 \pm 5$ \\
\hline $\mathrm{SaO}_{2} 5 \mathrm{~min}$ & $98 \pm 1$ & $98 \pm 2$ & $98 \pm 1$ & $98 \pm 2$ \\
\hline $\mathrm{SaO}_{2} 30 \mathrm{~min}$ & $98 \pm 1$ & $99 \pm 1$ & $99 \pm 1$ & $98 \pm 2$ \\
\hline $\mathrm{PACU} \mathrm{SaO}_{2} 0 \mathrm{~min}$ & $98 \pm 2$ & $97 \pm 3$ & $97 \pm 3$ & $96 \pm 3$ \\
\hline $\mathrm{PACU} \mathrm{SaO}_{2} 30 \mathrm{~min}$ & $99 \pm 1$ & $99 \pm 2$ & $99 \pm 2$ & $98 \pm 2$ \\
\hline
\end{tabular}

HR: heart rate; $\mathrm{SBP}$ : systolic blood pressure RR: respiratory rate; $\mathrm{PACU}$ : a post-anaesthesia care unit; $\mathrm{SaO}_{2}$ : arterial oxygen saturation.

Level of consciousness was assessed in the PACU using a four-point scale $(1=$ awake; 2 = drowsy; 3 = barely rousable to tactile or auditory stimuli; $4=$ asleep). Agitation in the PACU was also assessed using a four-point scale $(1=$ peaceful recovery; 2 = occasional sobbing/ mostly calm; 3 = crying but settles with reassurance; $4=$ thrashing around, crying and requiring restraint). Measurements were recorded every five minutes for 15 $\min$ and then every $15 \mathrm{~min}$ for an hour. The children were discharged from PACU when they were alert, active and tolerating oral fluids. The condition of the children after discharge from hospital was assessed by a telephone call to the parents during the $24-48 \mathrm{hr}$ period.

In order to assess interobserver variability, two observers evaluated 20 additional children who were premedicated with $0.5 \mathrm{mg} \cdot \mathrm{kg}^{-1}$ oral midazolam. The sedation' anxiolysis scores at the time of separation from the parents and mask acceptance were compared.

\section{Statistical analysis}

The number of patients required in each group was determined using power analysis ${ }^{3}$ based on the preliminary data by Feld $e t$ al. ${ }^{4}$ Assuming an incidence of excellent separation of $72 \%$ in the $0.75 \mathrm{mg} \cdot \mathrm{kg}^{-1}$ group and $90 \%$ in the $1.0 \mathrm{mg} \cdot \mathrm{kg}^{-1}$ group, $\alpha_{2}=0.05$ and $\beta=0.20,20$ patients were required in each group.

Parametric data were analyzed using one-way ANOVA and the Student - Newman Keuls test. Non-parametric data were analyzed using the Wilcoxon signed rank test, the Mann Whitney test and Chi square analysis. All data are means \pm SD unless indicated otherwise. $P<0.05$ was accepted.

Interobserver variability data were analyzed by kappa analysis (BMDP4F).

\section{Results}

Age, weight and duration of surgery did not differ among the groups (Table I). Heart rate, systolic blood pressure, respiratory rate and arterial oxygen saturation did not change in any of the groups during the study (Table II). There were no episodes of bradycardia, hypotension, bradypnoea, apnoea, airway obstruction, emesis or arterial oxygen desaturation at any time during the study. None of the children was sedated to the extent that they failed to respond to stimulation or were unarousable.

After premedication, the percent of children who were sedated and calm increased with time in all groups (Table III). However, all midazolam-treated groups were more calm and sedated than the placebo group at the time of separation from parents $(P<0.05)$ (Table III). Forty to sixty percent of children who were given midazolam were drowsy but responsive to verbal/tactile stimuli (sedation score of 3) at time of separation and $80-90 \%$ of the midazolam-treated children had excellent anxiolysis 
TABLE III Sedation scores after premedication

\begin{tabular}{|c|c|c|c|c|c|c|c|c|c|c|c|c|c|c|c|c|}
\hline & \multicolumn{12}{|c|}{ Time after premedication } & \multirow{2}{*}{\multicolumn{4}{|c|}{$\frac{\text { Event }}{\text { Separation* }}$}} \\
\hline & \multicolumn{4}{|c|}{$0 \min$} & \multicolumn{4}{|c|}{$15 \mathrm{~min}^{*}$} & \multicolumn{4}{|c|}{$30 \min t$} & & & & \\
\hline & 1 & 2 & 3 & 4 & 1 & 2 & 3 & 4 & 1 & 2 & 3 & 4 & 1 & 2 & 3 & 4 \\
\hline Placebo & 95 & 5 & 0 & 0 & 65 & 35 & 0 & 0 & 70 & 30 & 0 & 0 & 85 & 15 & 0 & 0 \\
\hline $0.5 \mathrm{mg} \cdot \mathrm{kg}^{-1}$ & 95 & 5 & 0 & 0 & 30 & 50 & 20 & 0 & 30 & 35 & 35 & 0 & 25 & 25 & 50 & 0 \\
\hline $0.75 \mathrm{mg} \cdot \mathrm{k}^{-1}$ & 90 & 10 & 0 & 0 & 45 & 20 & 35 & 0 & 30 & 20 & 50 & 0 & 20 & 20 & 60 & 0 \\
\hline $1.0 \mathrm{mg} \cdot \mathrm{kg}^{-1}$ & 100 & 0 & 0 & 0 & 40 & 45 & 15 & 0 & 35 & 25 & 40 & 0 & 35 & 25 & 40 & 0 \\
\hline
\end{tabular}

Data are percentages of patients in each treatment group.

*All midazolam groups differ from placebo $(P<0.05)$.

† Midazolam 0.75 and $1.0 \mathrm{mg} \cdot \mathrm{kg}^{-1}$ differ from placebo $(P<0.05)$.

TABLE IV Anxiolysis scores after premedication

\begin{tabular}{|c|c|c|c|c|c|c|c|c|c|c|c|c|c|c|c|c|c|c|c|c|}
\hline & \multicolumn{12}{|c|}{ Time after premedication } & \multicolumn{8}{|c|}{ Event } \\
\hline & \multicolumn{4}{|c|}{$0 \min$} & \multicolumn{4}{|c|}{$15 \min *$} & \multicolumn{4}{|c|}{$30 \min t$} & \multicolumn{4}{|c|}{ Separationt } & \multicolumn{4}{|c|}{ Mask acceptancet } \\
\hline & $l$ & 2 & 3 & 4 & $l$ & 2 & 3 & 4 & $I$ & 2 & 3 & 4 & 1 & 2 & 3 & 4 & 1 & 2 & 3 & 4 \\
\hline Placebo & 25 & 40 & 35 & 0 & 25 & 40 & 35 & 0 & 25 & 25 & 50 & 0 & 55 & 15 & 30 & 0 & 65 & 10 & 25 & 0 \\
\hline $0.5 \mathrm{mg} \cdot \mathrm{kg}^{-1}$ & 23 & 35 & 40 & 0 & 5 & 10 & 85 & 0 & 5 & 5 & 90 & 0 & 5 & 5 & 90 & 0 & 15 & 25 & 60 & 0 \\
\hline $0.75 \mathrm{mg} \cdot \mathrm{kg}^{-1}$ & 40 & 25 & 35 & 0 & 5 & 10 & 85 & 0 & 0 & 5 & 95 & 0 & 10 & 10 & 80 & 0 & 25 & 15 & 60 & 0 \\
\hline $1.0 \mathrm{mg} \cdot \mathrm{kg}^{-1}$ & 30 & 50 & 20 & 0 & 0 & 20 & 80 & 0 & 5 & 0 & 95 & 0 & 5 & 5 & 90 & 0 & 5 & 20 & 75 & 0 \\
\hline
\end{tabular}

Data are percentages of patients in each treatment group.

${ }^{*}$ Midazolam $0.75 \mathrm{mg} \cdot \mathrm{kg}^{-1}$ differ from placebo $(P<0.05)$.

$\dagger$ All midazolam groups differ from placebo $(P<0.05)$.

(anxiety scores of 3 or 4 ) at the time of separation from their parents. Sedation and anxiolysis scores at the time of separation were similar among midazolam groups (Tables III and IV). Application of a face mask at induction of anaesthesia was accepted more readily in those who were given midazolam than in those given placebo $(P<0.05)$; however, this acceptance did not differ among the three midazolam-treated groups (Table IV). The time interval from end of surgery to suitability to transfer to PACU, time to spontaneous eye opening in the PACU, and the time to discharge home from the PACU were similar for all four groups (Figure).

Untoward events noted during the study included: loss of balance, blurred vision and dysphoria. Loss of balance and head control were observed in nine children; four in the $0.75 \mathrm{mg} \cdot \mathrm{kg}^{-1}$ midazolam group (20\%), and five in the $1 \mathrm{mg} \cdot \mathrm{kg}^{-1}$ midazolam group (25\%). These incidences were greater than the zero incidence in the $0.5 \mathrm{mg} \cdot \mathrm{kg}^{-1}$ midazolam group $(P<0.05)$. Two children complained of blurred vision; one in the $0.75 \mathrm{mg} \cdot \mathrm{kg}^{-1}$ midazolam group and one in the $1 \mathrm{mg} \cdot \mathrm{kg}^{-1}$. One of the latter two children also experienced loss of balance. Dysphoric reactions were observed in two patients: one in each of the 0.75 and 1.0 $\mathrm{mg} \cdot \mathrm{kg}^{-1}$ midazolam groups, as evidenced by rapid alter- ations in mood. All untoward events either resolved or were resolving at the time of discharge from hospital. Two children (one in each of the 0.75 and $1.0 \mathrm{mg} \cdot \mathrm{kg}^{-1}$ midazolam groups) remained ataxic when they were discharged from hospital 75 and 90 min respectively after arrival in PACU. However, the ataxia was completely resolved by the following day.

Interobserver variability showed excellent agreement for all patients $(\kappa=1)$ except one in whom a $\kappa$ of 0.86 for anxiety score at the time of separation was reported.

\section{Discussion}

Although several studies have documented the effectiveness of oral midazolam as a premedicant compared with placebo or other premedicants, the optimal dose of midazolam required for adequate preoperative sedation and anxiolysis in children remains unclear. ${ }^{1,4,5,8-12}$ In a recent study by Feld et al., three doses of oral midazolam $\left(0.25,0.5\right.$ and $\left.0.75 \mathrm{mg} \cdot \mathrm{kg}^{-1}\right)$ were found to be equally effective for sedation and anxiolysis, although the separation of the children from their parents was excellent in less than $10 \%$ of cases. ${ }^{1}$ Our study was designed to detect a $25 \%$ improvement in separation/anxiolysis scores between 0.75 and $1.0 \mathrm{mg} \cdot \mathrm{kg}^{-1}$ midazolam with a power of 


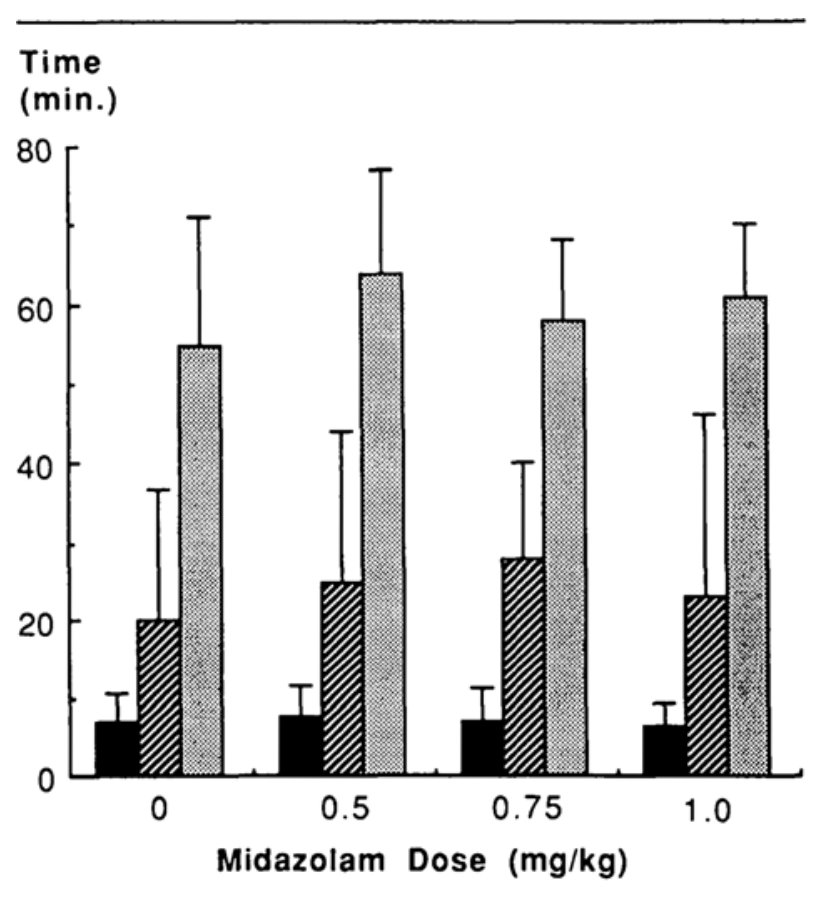

FIGURE Postoperative recovery intervals did not differ significantly among the four groups: Interval from the end of surgery until suitable for PACU. $\mathbb{Z}$ Interval from arrival in PACU until spontaneous eye opening, and Duration of PACU recovery until discharge. Data are means $\pm S D$.

$80 \%$. Since we did not achieve this improvement, we conclude that all three doses of midazolam, 0.5, 0.75 and $1.0 \mathrm{mg} \cdot \mathrm{kg}^{-1}$ are equally effective in providing sedation and anxiolysis in children at the time of separation from their parents $30 \mathrm{~min}$ after administration of the premedication.

We found that anxiolysis at the time of separation was excellent in $80 \%$ of the children who received midazolam compared with a 3-7\% incidence of excellent anxiolysis reported by Feld et al. ${ }^{1}$ The 10-25-fold greater success rate in effective separation in this study may be attributed in part to differences in study design. In the present study: (1) the age range of patients was narrow; (2) the time interval from administration of oral midazolam until separation was limited to $30 \mathrm{~min}$; (3) a different carrier vehicle/placebo for midazolam was used; and (4) atropine was omitted. The narrow age range selected might have minimized the impact of age-dependent differences in midazolam pharmacokinetic and pharmacodynamic behaviour reported previously in children. ${ }^{6}$ All assessments of sedation/anxiolysis at separation were made at 30 min after premedication, whether or not surgery was about to commence. Using this approach, all four groups were assessed at exactly the same time after premedication. In the study by Feld, however, the evaluation of sedation at the time of separation occurred any time between 30 and 80 min after administration of oral midazolam. ${ }^{1}$ Such a wide time interval limits interpretation of the pharmacodynamic effects of oral midazolam.

We used chocolate-cherry syrup rather than apple juice as the carrier vehicle and this might have resulted in different absorption rates of the midazolam. The chocolate-cherry syrup used is thick and flavourful and children are quite willing to swallow it. However, the syrup does not completely mask the bitter taste of midazolam. To maximize compliance, we recommend that the children should be instructed to ingest all of the premedicant in one swallowing motion.

The feasibility of oral midazolam administration for an ambulatory service was assessed by evaluation of (1) the speed and reliability of the onset of sedation and anxiolysis; and (2) the time required before the children were ready for discharge from the hospital. Eighty to ninety percent of patients who received midazolam had excellent anxiolysis at 30 min after administration of the premedication. Anxiolysis may have been excellent at 10 or 20 min after oral midazolam but this was not investigated in this study. The same may hold true for sedation. However, if these onset times did prove to be faster, separation from parents may also be effective after less than $30 \mathrm{~min}$ after the premedication. Further studies are required to determine the effectiveness of oral midazolam to smooth the separation of children from parents in less than $30 \mathrm{~min}$.

Children who received midazolam were suitable for discharge home approximately one hour after arrival in PACU. This recovery time is similar to that for the placebo group and similar to the usual time to discharge home after surgery. These data indicate that oral midazolam does not delay discharge from hospital after less than $40 \mathrm{~min}$ of halothane anaesthesia and is suitable for use in busy ambulatory units.

Admission and discharge policies in ambulatory surgery units vary from institution to institution. Patients arrive one hour before surgery and remain in the recovery room two hours or longer. ${ }^{112}$ In our ambulatory surgery unit, the admission policy is similar; however, patients are usually discharged home after one hour in the recovery room. We were able to incorporate this premedication regimen into our routine without delays in surgery or inconveniencing the families. We conclude that premedication with oral midazolam is feasible and consistent with the need for expeditious preoperative assessment and postoperative recovery generally demanded by an efficient ambulatory surgery unit.

In the present study, we evaluated the safety of oral midazolam during both preoperative and postoperative periods. There were no important circulatory, respiratory or long-term residual neurological effects observed in 
any of the children. The untoward effects noted (loss of balance, blurred vision, dysphoria) occurred only in children who received 0.75 and $1.0 \mathrm{mg} \cdot \mathrm{kg}^{-1}$. These data combined with the results of five different studies indicate that the incidence of serious complications after oral midazolam (0/400 children) is low. ${ }^{1,5,8-12}$ In a recent report, an 8-yr-old child who was premedicated with 0.5 $\mathrm{mg} \cdot \mathrm{kg}^{-1}$ oral midazolam, became unconscious after an $i v$ dose of erythromycin. ${ }^{7}$ This reaction was attributed to a drug interaction between midazolam and erythromycin. We conclude that oral midazolam is a safe premedication with few side effects provided the exclusion criteria above are respected.

In summary, our findings suggest that oral midazolam in a dose between 0.5 and $1.0 \mathrm{mg} \cdot \mathrm{kg}^{-1}$ is a safe and effective premedication for use in children from one to six years of age scheduled for ambulatory surgery. However, midazolam in doses greater than $0.5 \mathrm{mg} \cdot \mathrm{kg}^{-1}$ does not provide additional sedation or anxiolysis at $30 \mathrm{~min}$ after premedication and, in some instances, may be associated with loss of balance and head control as well as dysphoria and blurred vision. Oral midazolam premedication does not significantly prolong either the preoperative or postoperative period.

\section{References}

1 Feld $L H$, Negus $J B$, White PF. Oral midazolam preanesthetic medication in pediatric outpatients. Anesthesiology 1990; 73: 831-4.

$2 \mathrm{McCrea} J$. Extemporaneous oral liquid dosage preparations. The Canadian Society of Hospital Pharmacists 1988; 7.

3 Cohen J. Power Analysis for the Behavioral Sciences. London: Academic Press, Inc. 1977; 179-206.

4 Feld LH, Negus JB, White PF. Oral midazolam: optimal dose for pediatric premedication. Anesthesiology 1989; 71: A1054.

5 Feld LH, Urquhart ML, Feaster WW, White PF. Premedication in children: oral versus intramuscular midazolam. Anesthesiology 1988; 69: A745.

6 Payne $K$, Mattheyse FJ, Liebenberg D, Dawes $T$. The pharmacokinetics of midazolam in pediatric patients. Eur $\mathbf{J}$ Clin Pharmacol 1989; 37: 267-72.

7 Hiller A, Olkkola KT, Isohanni P, Saarnivaara L. Unconsciousness associated with midazolam and erythromycin. Br J Anaesth 1990; 65: 826-8.
8 Molter G, Altmayer P, Castor G, Buch U. Die orale pramedikation mit midazolam bei kindern. AnaesthesiolReanim 1991; 16: 328-33.

9 Payne KA, Coetzee AR, Mattheyse FJ, Dawes T. Oral midazolam in pediatric premedication. South African Medical J 1991; 79: 372-5.

10 Sjovall S, Kanto J, Lisalo, et al. Midazolam versus atropine plus pethidine as premedication in children. Anaesthesia 1984; 39: 224-8.

11 Saarnivaara L, Lindgren L, Klemola UM. Comparison of chloral hydrate and midazolam by mouth as premedicants in children undergoing otolaryngological surgery. $\mathrm{Br} \mathbf{J}$ Anaesth 1988; 61: 390-6.

12 Brzustowicz RM, Nelson DA, Betts EK, Rosenberry KR, Swedlow $D B$. Efficacy of oral premedication for pediatric outpatient surgery. Anesthesiology 1984; 60: 475-7. 